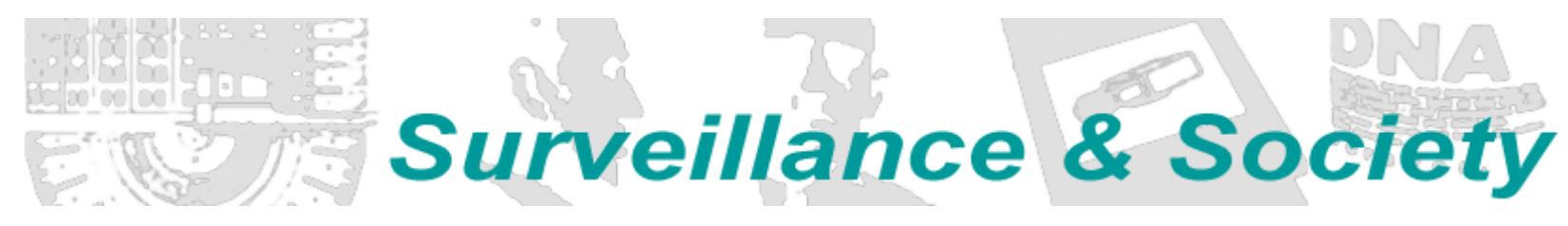

\title{
\begin{tabular}{l|l} 
Article & $\begin{array}{l}\text { Constructing Empowerment Through } \\
\text { Interpretations of Environmental Surveillance } \\
\text { Data }\end{array}$
\end{tabular}
}

\section{Gwen Ottinger}

University of Washington-Bothell, USA. ottinger@u.washington.edu

\begin{abstract}
Environmental surveillance data - in particular, data from air monitoring conducted by grassroots community groups-is presumed to empower community members with respect to neighboring industrial facilities; furthermore, extensions of datacollecting ability are assumed to represent expansions of empowerment. This paper challenges the idea that empowerment follows from the collection of copious surveillance data, arguing instead that the degree and kind of empowerment environmental surveillance supports is determined by the manner in which surveillance data is made meaningful. Examining contrasting interpretations of environmental surveillance data, the paper shows how they variously construct empowerment in terms of the power to define issues, the power to enforce laws, and the power to choose. The three forms of empowerment vary in the level at which they enable community groups to act-suggesting that the empowering potential of surveillance rests in large part on strategic interpretive choices.
\end{abstract}

\section{Introduction}

On April 21, 2005, residents of Chalmette, Louisiana, put Exxon Mobil's Chalmette Refinery under surveillance. Working with an environmental justice non-profit called the Louisiana Bucket Brigade (LABB), St. Bernard Citizens for Environmental Quality (SBCEQ) installed an expensive air monitor to measure ambient concentrations of six toxic chemicals released by the refinery. Real-time data from the Sentry monitor were posted online, allowing residents to see, at any time, the levels of benzene, toluene, xylene, carbon disulfide, hydrogen sulfide, and sulfur dioxide that they were breathing (Cannizaro and Barbier 2005).

The Chalmette Air Monitoring Project (CHAMP) was an extension of the community group's on-going efforts to monitor the refinery's effects on air quality. Residents had previously measured concentrations of air toxins using "bucket" air samplers and filmed flares and accidents at the refinery with home video equipment (Louisiana Bucket Brigade n.d.). Moreover, CHAMP mirrored environmental surveillance activities in numerous other "fenceline communities," where resident-activists have used a variety of strategies and devices, including the bucket and the Sentry, to watch the environmental impacts of neighboring industrial facilities.

Efforts by communities to monitor industry's effects on air quality can be considered a form of "sousveillance" (Mann, Nolan, and Wellman 2003). Although they lack the element of "reflectionism"community members are not subject to surveillance by industrial facilities - they nonetheless constitute

Ottinger, Gwen. 2010. Constructing Empowerment Through Interpretations of Environmental Data.

Surveillance \& Society 8(2): 221-234.

http://www.surveillance-and-society.org | ISSN: 1477-7487

(C) The author, 2010 | Licensed to the Surveillance Studies Network under a Creative Commons

Attribution Non-Commercial No Derivatives license. 
"surveillance from below." Like other kinds of sousveillance, community environmental monitoring explicitly aims to empower the surveyors. Through their monitoring, community groups expect to gain advantage over neighboring companies in campaigns seeking environmental clean-ups and community relocation. And because they allow residents to monitor companies' activities continuously, real-time monitors like the Sentry are regarded by residents and their non-profit allies as the most powerful of the available tools.

But the assumption that environmental surveillance is empowering - and that continuous surveillance is especially so-begs a number of questions central to our understanding of the relationships between surveillance (or sousveillance) and empowerment. In what way(s) are residents empowered by air monitoring? How effective have different forms of monitoring been in furthering communities' campaign goals? What advantages does continuous monitoring confer over more sporadic forms of "watchdogging," including air sampling with buckets?

In this paper, I argue that the degree and kind of community empowerment fostered by environmental surveillance depends not on the extent of the data produced by monitoring, as tends to be assumed. It depends, rather, on how those data are interpreted. Empowerment, I suggest, is constructed in the process of making surveillance data meaningful, and its nature varies depending on the contexts chosen for interpretation.

My argument draws on qualitative research conducted in three Louisiana communities - Chalmette, New Sarpy, and Norco - each along the Mississippi river within 30 miles of New Orleans, and each adjacent to one or more major petrochemical facilities. In the course of ethnographic research during an environmental justice campaign in New Sarpy (2002 - 2003), I observed residents' use of buckets and bucket data in their struggle against the refinery next door; I also conducted semi-structured interviews (whose topics included air quality and air monitoring) with residents of both New Sarpy and the neighboring town of Norco, representatives of petrochemical facilities in both towns, environmental regulators, and organizers at non-profits that supported the communities. In 2007, I interviewed CHAMP participants and other users of real-time monitoring technologies about their experience with the new devices. Finally, since 2001, I have maintained a relationship with LABB, an environmental justice nonprofit that assisted offered both organizing assistance and technical support to campaigns in New Sarpy, Norco, and Chalmette, volunteering in a variety of capacities over the years. This volunteer work has, at moments, made me a peripheral participant in the struggles over interpretation that this paper describes: at one point, for example, I created an automated tool to allow bucket users to compare their measurements to government standards and screening levels; at another, I supervised a group of engineering students working to make meaningful Sentry data in which no violations of laws were apparent. While in every case it has been environmental justice activists who have identified the need for this interpretive work, undertaking it on their behalf has helped me to understand - to an extent that would not have been possible through interviews alone - their use of monitoring data as explicitly aimed at disrupting, and providing alternatives to, regulators' interpretations of data.

Episodes from these three communities - while not necessarily representative of the many communities across the globe that use air monitoring, especially buckets, to conduct environmental surveillance-can nonetheless offer insight into the range of available possibilities for interpreting monitoring data and the variation in the kinds of empowerment constructed in each. Depending on the contexts in which data from surveillance is made meaningful, "empowerment" for communities can refer to residents' power to define environmental issues, to enforce environmental laws, or to choose their environmental circumstances. These forms of empowerment are not equally potent. Increased power to define environmental issues contributes to community members' ability to challenge established structures of environmental decision-making and environmental injustice; the added power to enforce laws increases residents' status within those structures. But the power to choose, as we shall see, individualizes 
environmental action with double-edged consequences: while potentially increasing community members' knowledge of local risks, this mode of interpretation also opens them to blame for not making better choices. Among the contributions of this study, then, is to show how "empowerment" constructed in the context of neoliberal models of choice can in fact constrain empowered individuals' ability to push for structural change.

In the next section, I argue that the interpretation of data, while a constitutive aspect of the power dynamics associated with surveillance, has received relatively little attention in discussions of sousveillance or resistance to surveillance. After describing the evolution and variety of air monitoring activities in fenceline communities in the third section, I briefly recount the complicated contexts in which communities and other groups struggle to make environmental surveillance data meaningful. Section five examines three contrasting modes of interpretation - as exemplified by a report on bucket results in New Sarpy, use of Sentry data in Chalmette, and presentation of findings of an industry-sponsored air monitoring program in Norco-showing how "empowerment" is constructed in each. Understanding the relationship between interpretation and empowerment, I argue in the paper's conclusion, is essential to sociological understanding of the relationship between surveillance, inequality, and empowerment, including understanding of the ways that data can either subvert or play into neoliberal forms that have been shown to heighten inequality (e.g. Collins et al. 2008). Further, these understandings can inform effective mobilization of surveillance technologies by relatively powerless or marginalized groups.

\section{Interpretation and Surveillance-from-below}

In its contemporary form, surveillance is undertaken with an eye to intervention. That is, surveillance is not simply the act of watching, of collecting numbers, images, and other data to track activity. A second, constitutive part of surveillance is the goal of, in David Lyon's terms, "influencing or managing those whose data have been garnered" (Lyon 2001, 2).

In principle, individuals may be influenced by the fact of surveillance itself: one will be on his best behavior when he knows he is being watched, or so the theory goes. But in practice, the mechanisms through which data become a tool for influencing people or managing populations - that is, for exercising power-are often far more complicated. Surveillance studies has, in particular, highlighted the infrastructures involved in transforming data into interventions. These include computational tools, which aggregate data about individuals to create populations that can be acted on (Willse 2008; Guzik 2009), and technological systems, which integrate individualized surveillance technologies into existing programs for centralized decision-making and social control (Monahan and Wall 2007). Regulatory regimes, while often left implicit in studies of surveillance practices, are also central to the processes through which data becomes actionable information: surveillance to prevent crime or determine compliance uses laws and regulations as the basis for evaluating the data collected and deciding how to intervene (see for example Minnaar 2007; Gad and Lauritsen 2009).

The power dynamics entailed in a surveillance episode depend in large part on its interpretation and intervention aspects. Research on surveillance and inequality in particular suggests myriad ways that power is asserted and inequalities reinforced through regulation, classificatory systems, and computer algorithms that help actors engaged in surveillance to determine how to intervene on the basis of surveillance data (Doherty et al. 2008; Kenner 2008; Pallitto and Heyman 2008). However, attempts to disrupt the power relations associated with various forms of surveillance have largely engaged with the act of surveillance itself, attempting to prevent the collection of accurate data (Marx 2003) rather than challenging the processes through which those data are used to influence or manage those under surveillance. Nor have interpretation and intervention been a focus of counter-surveillance activities, which turn the camera back on surveying entities. Except where counter-surveillance has shown police officers and other officials breaking the law, little attention has been paid to the mechanisms through 
which data collected "from below" could be interpreted to allow its collectors to exert influence over more powerful actors or institutions. (Monahan 2006 makes a related critique.)

Understanding the potential of surveillance to empower marginalized groups, then, requires a better understanding of the relationship between sousveillance data and intervention. What are the infrastructures that give meaning to data collected through surveillance-from-below? How do they exert influence or compel action? And in what ways do they rely on, disrupt, reinforce, or reconfigure existing power relations?

\section{Surveillance in the Environmental Justice Movement}

St. Bernard Citizens for Environmental Quality's (SBCEQ) use of the Sentry air monitor to put the Chalmette refinery under surveillance is but one example of a widespread trend in the environmental justice movement (EJ): the use of air monitoring technology by community groups to watch neighboring industrial facilities.

While residents of fenceline communities have always been in a position to observe flares, fires, and unusually large releases of odiferous chemicals from their industrial neighbours, systematic surveillance of facilities and their impacts on air quality arguably began with the advent of "bucket brigades" in the mid-1990s (O'Rourke and Macey 2003; Overdevest and Mayer 2008 discuss the history of bucket brigades). Now an integral part of community organizing in hundreds of fenceline neighborhoods around the world, bucket brigades revolve around an air sampling device known as the bucket. The bucket, shown in figure 1, enables residents without scientific training to measure levels of hazardous pollutants in their air: a bucket collects a sample of the ambient air in a non-reactive plastic bag; the sample is then sent to a commercial laboratory, which uses a standardized procedure to determine chemical concentrations (see Ottinger 2010 for a more detailed discussion). In bucket brigades, episodic surveillance with buckets - which produce short-term "snapshots" of air quality during especially malodorous periods - is often complemented by lower tech forms of monitoring. One bucket brigade handbook, for example, encourages community members to keep a log book that records the date and time of "pollution incidents" and to use video cameras to document flares and smoke from facilities (Larson 2002).

As environmental justice activists became experienced with buckets, they sought other air monitoring technologies that could expand their ability to track industrial facilities' effects on local air quality. In fall 2002, for example, the Louisiana Bucket Brigade (LABB) and the Texas SEED Coalition, two non-profits groups working with fenceline communities throughout the Gulf region, worked with a professor at Massachusetts Institute of Technology to test a number of hand-held air monitors to see how well they would work in community contexts. By 2005, activists had embraced two devices manufactured by the Cerex Corporation (later to become Argos Scientific). The Sentry, which SBCEQ and LABB deployed in Chalmette, beams ultraviolet light at a sensor positioned some distance away (about 100 yards is desirable) and produces real-time readings of chemical concentrations in the intervening air. The Hound is a portable version of the Sentry. Integrating light source and sensor into one black box about a yard long and a foot square (see figure 2), the Hound is particularly popular with community groups and their non-profit allies. Most commonly used for intermittent, drive-by surveillance - collecting real-time data about air toxics concentrations at random times in the parts of a community perceived to be most polluted - the Hound is considered an advance over the bucket, at least in terms of its ability to document industry's environmental effects. Like the Sentry, it produces a steady stream of data-a moving picture to the bucket's snapshot. 


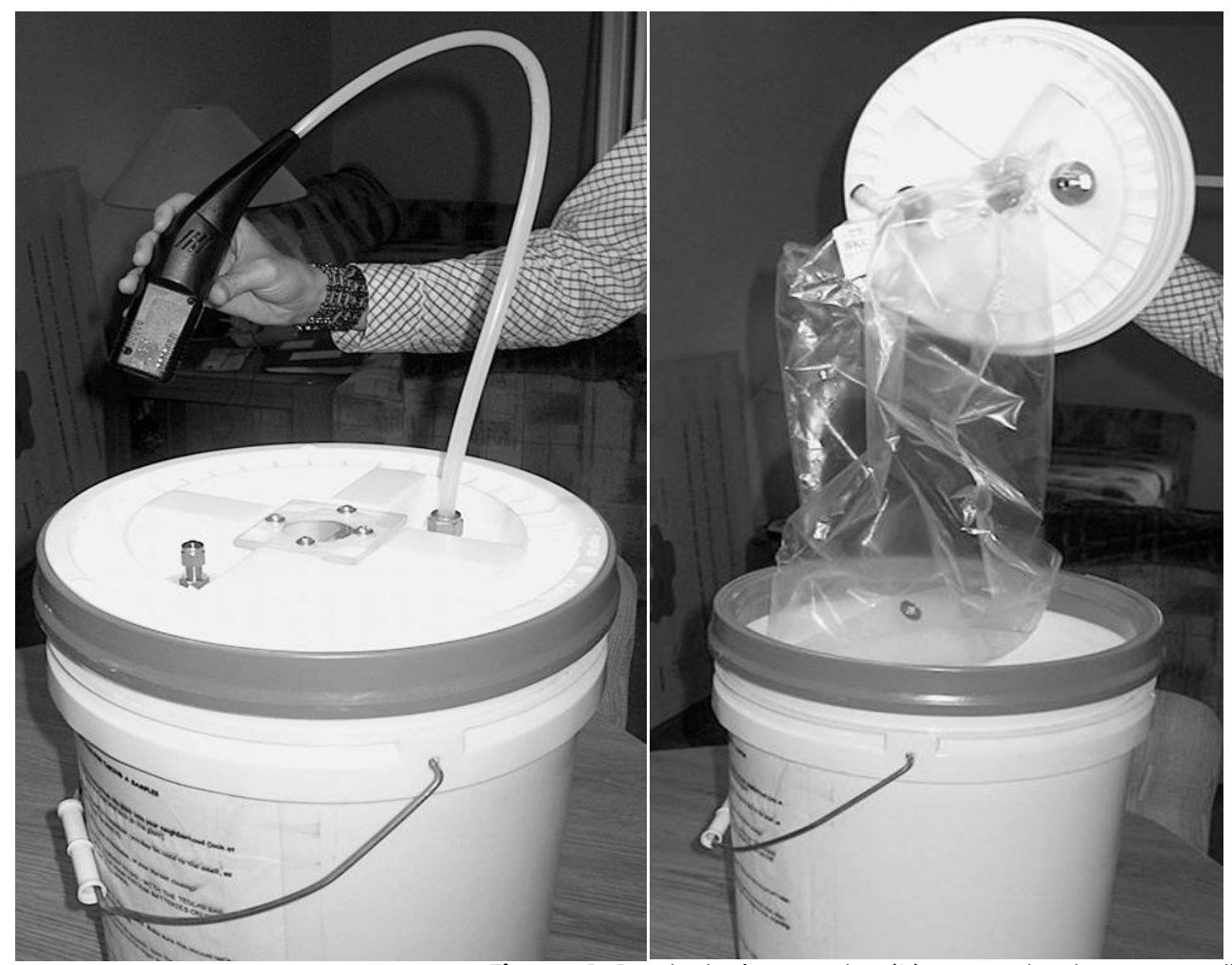

Figure 1: Bucket air sampler (L), open to show sampling bag (R)

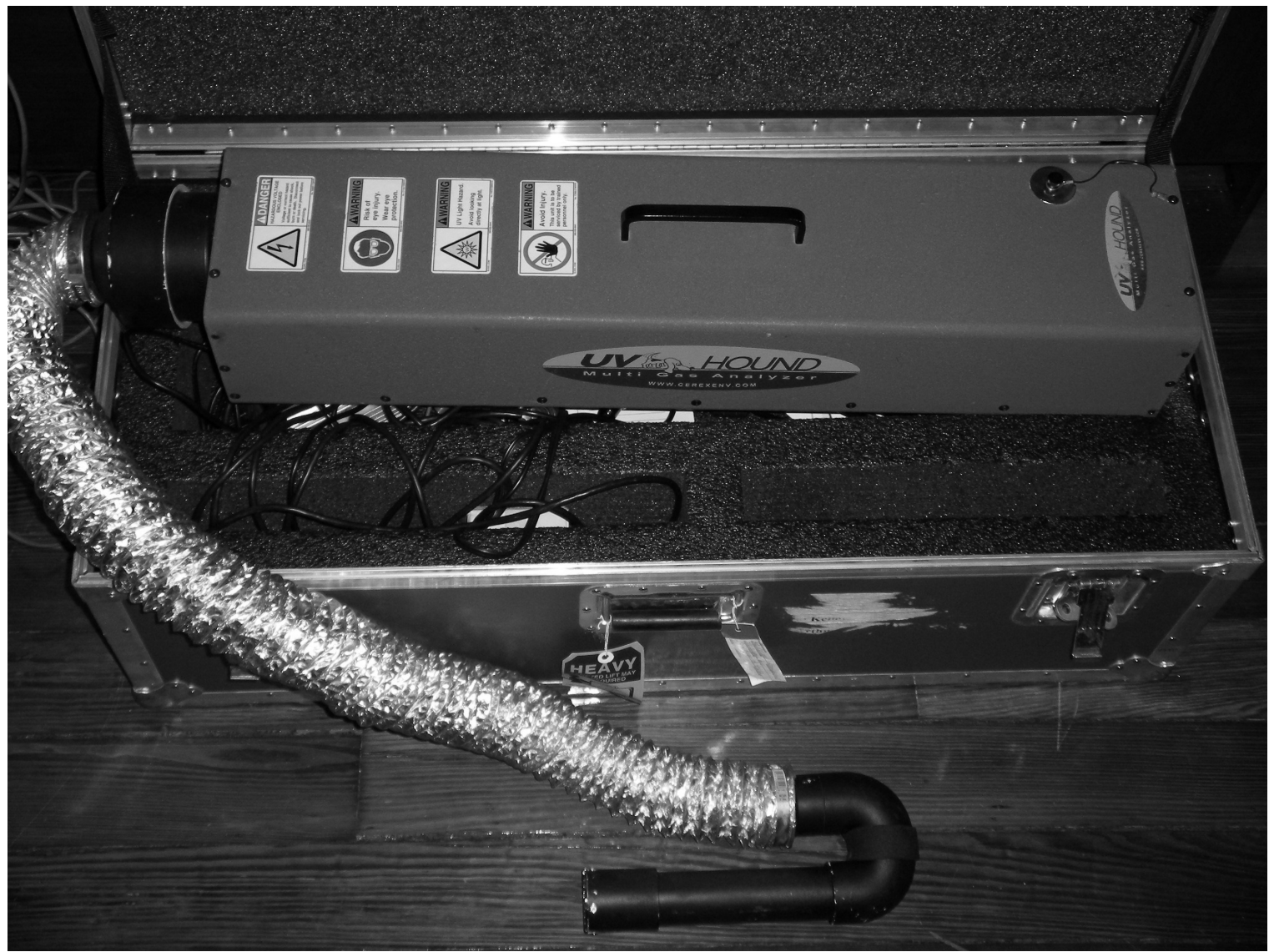

Figure 2: The Hound air monitor 
In addition to using buckets, Hounds, and Sentries to monitor nearby facilities, environmental justice activists used their air monitoring efforts to push for increased, official surveillance of industrial pollution. In many communities, including Chalmette, seeing sophisticated monitors like the Sentry installed at the fenceline of the neighboring facility was an explicit campaign goal. Community activism in fact succeeded in expanding surveillance capacity in numerous cases, though the group responsible for surveillance has differed from case to case. In Chalmette, the state environmental regulatory agency, the Louisiana Department of Environmental Quality (LDEQ), set up three new, real-time monitoring systems around the Exxon Mobil refinery. In other places, the industrial facility itself agreed to establish a monitoring program; several northern California refineries operate Sentries at their fencelines, and others, like Shell Chemical in Norco, Louisiana, monitor air quality in the community using a sampler-based protocol that mimics the one used by regulatory agencies (see Ottinger 2010). Finally, some communities have won their own monitoring equipment in consent decrees with neighboring facilities: the Eastwick neighborhood of Philadelphia, for example, owns both a Hound and a Sentry as a result of a consent decree with the neighboring Sunoco refinery, though the difficulty of setting up and maintaining the Sentry has thus far prevented them from deploying it.

Regardless of who has primary responsibility for operating monitors, communities that have won expanded air monitoring programs through their campaigns have access to monitoring data. Typically, data from real-time monitors is made available on a website, allowing community members to watch fluctuations in chemical concentrations in (almost) real time, and to check monitor readings when they experience foul odors. (Data from sampling, like that in Norco, is provided to residents in periodic reports.) Community agitation for increased monitoring by industry and agencies, no less than environmental justice activists' own monitoring with buckets and Hounds (and, more rarely, Sentries), has thus increased their capacity for surveillance of neighboring industrial facilities.

\section{Contexts of Environmental Surveillance}

Monitoring data collected in fenceline communities, whether by residents, industrial facilities, or regulatory agencies, ultimately takes on meaning in the overlapping contexts of grassroots environmental justice campaigns, contested environmental health science, and regulatory standards for air quality.

In a community campaign, residents concerned about pollution from a neighboring industrial facility, and its effects on their health, organize demand action from the facility (Ryder 2006). In extreme cases like Norco, Louisiana, residents may want the facility to relocate them because of fears for their health and safety (Lerner 2005). In other cases, they may want the facility to make specific environmental improvements - among SBCEQ's demands, for example, was the phase-out of hydrogen fluoride (HF), an especially toxic chemical. Where community groups have organized against neighboring facilities, their pollution- and health-related grievances are typically compounded by frustration with industry representatives' treatment of residents. Community members may feel that facility officials are disrespectful to residents, dismissive of legitimate concerns, and deceitful about their environmental records (Ottinger 2005, 120-125). In many cases, decision-makers even refuse to meet with community groups (Ryder 2006). In this context, residents look to air monitoring to document a facility's environmental impacts, show that officials are lying when they assert that their facility does not have any impact, and to intensify the pressure on decision-makers to negotiate with the community.

Among the factors making for contentious relations between industrial facilities and their residential neighbors is the state of knowledge about environmental health. Fenceline communities are often convinced that their members suffer from higher rates of certain diseases than people who live further away from industrial facilities, and that they are sicker because of pollution from a nearby facility. These local understandings, however, are rarely borne out by scientific studies, for a series of reasons. Standards for statistical significance make it very difficult to prove elevated rates of disease in small population like 
those of fenceline communities (Allen 2000). Causal links between chemical exposures and health effects are also notoriously hard to demonstrate (Bryant 1995; Head 1995; Tesh 2000). And studies that have the potential to show pollution's effects on community health are unlikely to be conducted in the first place, as a result of the way that scientific research is funded and rewarded (Frickel et al. 2010; Frickel 2008; Hess 2007). The result is persistent conflict between, on the one hand, community groups, environmentalists, and sympathetic scientists who believe that appropriately designed studies would show that pollution harms the health of fenceline communities and, on the other hand, representatives of chemical companies who defend the authority of a body of knowledge that shows no causal connection between industrial pollution and community health. Air quality monitoring fans the flames of this conflict by documenting residents' exposures to chemicals without being able to contribute to understanding the health effects of those exposures.

Regulatory standards for air quality also help define the contexts for monitoring in fenceline communities, albeit incompletely. The U.S. government regulates ambient air levels of only six pollutants: nitrogen oxides, sulfur oxides, particulate matter, ozone, lead, and total volatile organic compounds (VOCs). Air monitoring conducted and called for by environmental justice groups, in contrast, focuses on specific VOCs, known also as hazardous air pollutants or air toxics, including benzene, toluene, xylene, methyl ethyl ketone, carbon disulfide, and hydrogen sulfide. Of the "criteria pollutants" regulated by the US Environmental Protection Agency, only sulfur dioxide is measured by the Sentry and Hound; none are measured by buckets. Several state governments, including Louisiana and North Carolina, have ambient air standards for hazardous air pollutants. Other states and federal agencies like the American Toxics Substances and Disease Registry publish non-regulatory screening levels that define thresholds for safe ambient concentrations of chemicals. The scientific uncertainties around health impacts of chemical exposures reverberate through all of these governmental attempts to set limits on toxic chemicals in the ambient air (Tesh 2000): although all of the standards or screening levels are based on health studies, the limits set by different agencies for a single chemical can vary by orders of magnitude. The incompleteness of regulatory standards for hazardous air pollutants has arguably been a factor in industrial facilities' willingness to submit to environmental surveillance - a refinery would be far more reluctant to install a Sentry if the data collected could be used by a regulatory agency as the basis for a penalty (personal communication with Don Gamiles, January 22, 2008). However, it also allows monitoring data to be interpreted in multiple, often conflicting ways.

\section{Empowering Interpretations}

Community-industry conflict, contested health science, and incomplete regulatory standards together give meaning to air monitoring data from fenceline communities. Residents, their non-profit allies, industrial facilities, and regulatory agencies all participate in interpreting data and, in the process, relate surveillance data to potential interventions. Community empowerment is a theme in various interpretations; however, the different interventions they suggest each structure empowerment quite differently.

\section{Power to Define Issues}

At LABB, an elderly African-American woman named Dorothy Jenkins is held up as an exemplar of environmental surveillance-from-below. Over a two-year period beginning in 2000, Jenkins took several bucket samples in her front yard in New Sarpy, Louisiana, to document the effects of the oil refinery right across the street. Although she was an especially dedicated sampler, it was what she did with the results that made her something of a legend. In an oft-recounted incident, Jenkins met with the plant manager of the neighboring Orion refinery and complained about a release that had fouled the air in her community. The plant manager insisted that there had been no release from the refinery that day. At that point, the story goes, Jenkins whipped out the results from a bucket sample taken during the alleged release and thrust them in front of the plant manager. "Then tell me why there was benzene in my neighborhood at levels that violate state standards?" an LABB fundraising pamphlet quotes her as asking. 
The story offers a window into a common way of interpreting environmental surveillance data, especially bucket results, and the kind of empowerment it implies. Bucket results here were not used in conjunction with health studies or other data in an attempt to prove that the Orion refinery was harming residents' health. Instead, they took on meaning in light of the refinery manager's assertion that there had been no release. In that narrow context, they upset the usual power dynamic between the white, male engineer representing a multi-million dollar company and the retired cafeteria worker who lived next door. Where refinery officials had previously been able to assert their expertise to brush off residents' complaints, Jenkins's bucket data demanded an explanation. Throwing the results of her surveillance down like a gauntlet, Jenkins put the refinery manager on the defensive, forcing him to respond to her question.

This kind of table-turning maps on to a form of empowerment that veteran community organizer Paul Ryder calls "taking the initiative." Conceived as central to fenceline community groups' ability to win campaigns that target local facilities, "taking the initiative means that you are taking the actions that define what the campaign is about. Everyone else is just reacting to your actions" (Ryder 2006, 43). When a community group can define the issues - and keep the more powerful company in the position of having to react-Ryder suggests, it can force the company to take its grievances seriously and to negotiate a resolution that makes conditions in the community better.

As Jenkins's question to the plant manager suggests, regulatory standards for air quality are a second important context for interpreting bucket data. But her comparison between bucket data and regulatory standards also represented an attempt to take the initiative, to define the campaign issues to which more powerful entities would have to respond. The state standards to which her question referred regulate annual average levels of benzene; Jenkins's bucket data reflected air quality over a period of several minutes. Technically, the two numbers were incommensurable - but by comparing them, as bucketwielding residents routinely do, Jenkins pushed to define the problem of air quality in her community as one of extreme levels of chemicals during releases, rather than annual average levels.

Activists' interpretations of bucket results in the context of state standards, then, imagine empowering community members by forcing not only industrial facilities but also regulatory agencies onto the defensive. The point is highlighted by table of results from six bucket samples presented in Land Sharks: Orion Refining's Predatory Property Purchases, a report released in late 2001 by Concerned Citizens of New Sarpy and LABB (see figure 3). Organized by chemical, the table describes the associated health effects for each of four air pollutants, lists the screening level published by the neighboring state of Texas and the regulatory standard set by Louisiana ("none" in three of the four cases), and reports measured concentrations that, for the most part, exceed the screening levels. Like the high benzene reading on a day when Orion claimed not to have had a release, the lack of regulatory standards for chemicals with dangerous-sounding health effects (e.g. "attacks the nervous system"), present in the community at levels an order of magnitude greater than a neighboring state considers healthy, demands an account. Then why, we might imagine Jenkins saying to an LDEQ representative, are there no regulations for what's in my air?

Further, interpreting bucket data in the context of incomplete regulatory standards for air quality is imagined to offer an additional opportunity for communities to empower themselves with respect to neighboring companies, as a chapter of Paul Ryder's Good Neighbor Campaign Handbook devoted to community environmental surveillance makes clear. In it, bucket promulgator Denny Larson argues that, in the absence of regulatory standards for ambient levels of most air toxics, community groups should set their own standards: 
Hydrogen Sulfide:

Attacks the respiratory system Texas Screening Level: 1 ppb Louisiana State Standard: None

January 29, 2001

February 21, 2001

August 31, 2001

Carbonyl Sulfide

Attacks the nervous system Texas Screening Level: 1 ppb Louisiana State Standard: None

August 30, 2000

February 21, 2001

June 7, 2001
5.09

5.75

2.17

22.2

2.3

2.58

\section{Carbon Disulfide:}

Attacks the respiratory system Texas Screening Level: 1 ppb Louisiana State Standard: None

August 30, 2000

October 1, 2000

40

February 21, 2001

1.4

June 7, 2001

2.4

3.8

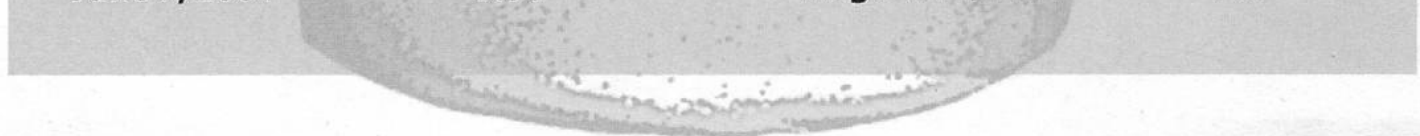

Figure 3: Presentation of Bucket Results in Land Sharks report

For much of what the companies are discharging, however, there isn't a legal standard of what can be in the air in your neighborhood, so any amount is legal. You can still say, "Let's say you're in compliance with the law, you're not in compliance with me living here. I can't stand the stink. I'm not going to take this pollution raining down on me any more. Here's my compliance standard for your company and you're going to meet that." (Larson 2006, 73).

Environmental monitoring data that reveal the holes in regulatory standards, then, offer communities an opening to define the issue of air quality, to set standards to which the company must react.

Interpretations of bucket results that give surveillance data meaning in the context of plant manager assertions and incomplete regulatory standards thus construct community empowerment in a particular way: an empowered community is one able to define local environmental issues and force other actors to respond to them. The degree to which community activists are able to achieve this kind of empowerment through environmental surveillance varies greatly from community to community, and activists' redefinitions of air quality issues are, in the face of regulatory standards, tenuous at best (Ottinger 2010). Regardless of the extent to which it is realized, however, the model for empowerment is significant in light of the contrasting ways that other interpretations of environmental surveillance data construct empowerment.

\section{Power to Enforce Laws}

In April 2005, SBCEQ took environmental surveillance-from-below to a new level. Working with the Louisiana Bucket Brigade, they set up a Sentry monitor in the community to track the impact of the 
neighboring Exxon-Mobil refinery. For nearly two months, the Sentry took a measurement of toxic chemicals in the air once every minute, around the clock. While simply mobilizing the technology to watch the refinery constantly was an accomplishment in itself, the way SBCEQ was able to use the data made their monitoring especially powerful. Within the first week of operating the monitor, the LABB volunteer overseeing the technical aspects of the project identified a period during which average sulfur dioxide $\left(\mathrm{SO}_{2}\right)$ levels exceeded the National Ambient Air Quality Standards for 24-hour average levels of $\mathrm{SO}_{2}-$ a finding SBCEQ and LABB publicized soon after in a press release:

During a 24 hour period that began at $6 \mathrm{AM}$ on April $28^{\text {th }}$, the monitor detected readings of sulfur dioxide - known to trigger asthma attacks - at levels that violate EPA standards.

The air is allowed to exceed the EPA limit once per year; the level was exceeded within the first week of operating the monitor. (Rolfes and Ford 2005)

Using the federal standards to make environmental surveillance meaningful, the press release stressed that community monitoring with the Sentry had done something that buckets could not: show conclusively that Exxon-Mobil was running afoul of the law.

While this presentation of monitoring data has similarities with the ways bucket data was mobilized in New Sarpy, the version of empowerment that it constructs is importantly different. Both interpretations invoke regulatory standards; however, the presentations of bucket data discussed in the last section do so in a way that highlights the incompleteness and inadequacies of the standards. The Sentry finding, in contrast, draws on the authority of the regulatory standard to underscore the significance of surveillance data. Moreover, while Chalmette residents, just like New Sarpy residents, used their air monitoring data to put the neighboring refinery on the defensive, their interpretation of Sentry results in the context of the EPA standard does not redefine the issue of air quality, as CCNS's use of bucket results does; rather, it uses the established infrastructure of regulatory standards to establish the seriousness of the problem.

Interpreted in the context of authoritative (as opposed to incomplete) regulatory standards, environmental surveillance empowers communities with respect to neighboring companies by allowing them to borrow, and even extend, the state's power over industrial facilities. Through monitoring, community members become potential enforcers of environmental laws - a role, in fact, made available to them in the Clean Air Act more generally through its provision for citizen enforcement suits. Community-based monitoring also expands the state's capacity for surveillance of industrial pollution and, in turn, its ability to determine compliance. In this construction, then, an empowered community is a community with the ability to participate alongside regulators in the enforcement of environmental laws.

The two versions of empowerment co-exist in community environmental surveillance projects, of course. LABB and SBCEQ also looked at their data in ways that challenged the adequacy of regulations (interview with Brian Swett, July 25, 2007), and bucket users in New Sarpy and elsewhere strive to participate in environmental enforcement (O'Rourke and Macey 2003). The distinction is nonetheless important because of the different political possibilities entailed in the two forms of empowerment. Interpretations of surveillance data that leverage regulatory agency authority for community empowerment are likely to garner the most concrete, near-term results for community groups-ExxonMobil was cited for its violations under the Clean Air Act as a result of SBEQ's efforts (Sanborn 2005) because of the robustness of standards described in the last section. On the other hand, empowerment that figures community members as participants in enforcement restricts their ability to challenge the adequacy of legal and regulatory frameworks - a kind of intervention central to the initiative-taking, issue-defining form of empowerment. 


\section{Power to Choose}

Following bucket monitoring by residents, in 2002 a Shell Chemical facility in Norco, Louisiana, put itself under surveillance. Rather than installing a real-time monitor like the Sentry, as a number of its counterparts had, or would, Shell set up six monitoring stations in Norco's two square miles of residential area and, following a protocol used by the LDEQ in its air toxics monitoring program, determined chemical concentrations with 24-hour samples taken every sixth day. At the end of the first three months of monitoring, the company presented its results to the community. As one would expect, they compared their data to the LDEQ's regulatory standards-omitting the chemicals detected in the samples but not regulated by the state - to show that air toxics levels in Norco were within the legal limits. But Shell's presentation to the community also included a less obvious interpretation: in a graph entitled, "Norco's Air is Similar to Other Cities," average values of 1,3-Butadiene measured at Norco's six monitoring stations were compared to levels measured by the EPA in 5 other cities, including Houston and Minneapolis (figure 4).

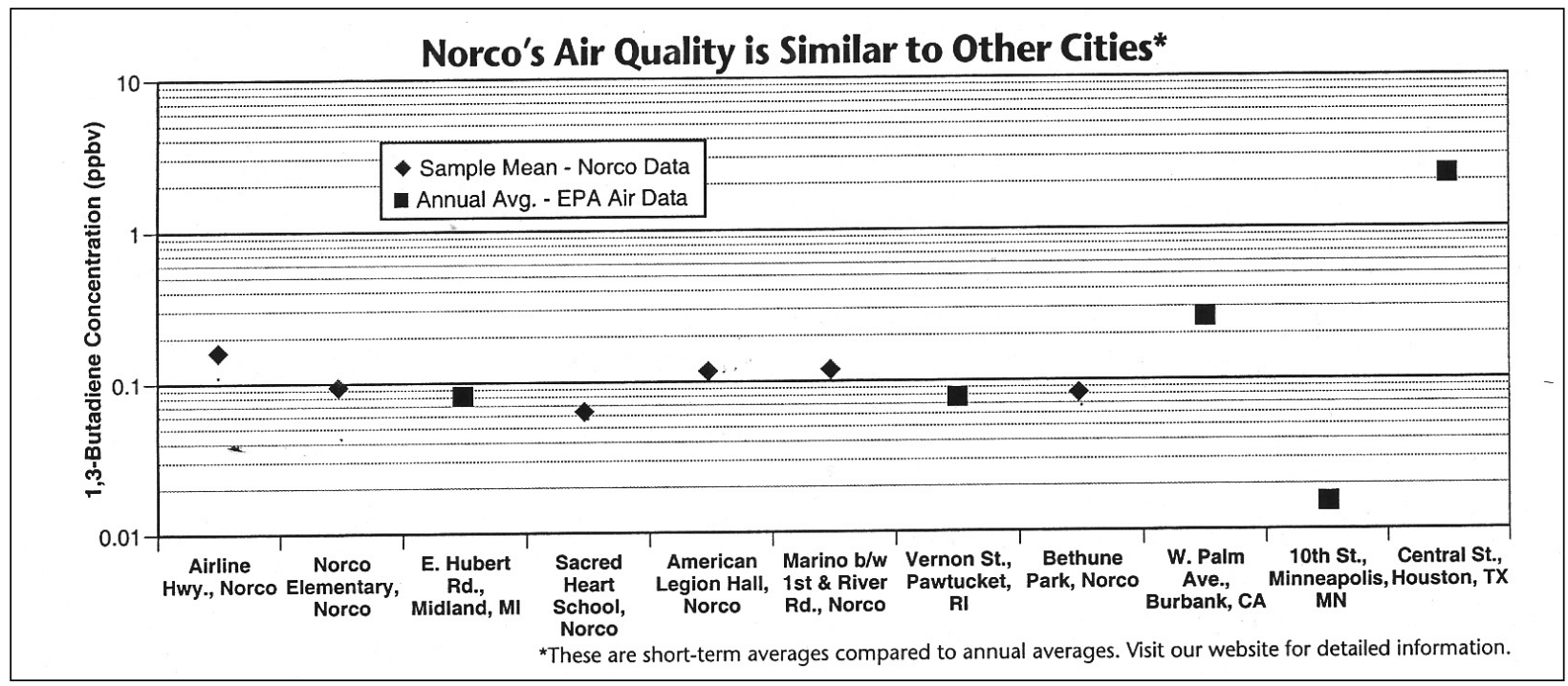

Figure 4: Interpretation of Air Monitoring Data by Shell Chemical

Putting environmental surveillance data in the context of air quality measurements in other cities, Shell chemical representatives constructed a third version of empowerment. Discussing the graph in a media briefing, Shell's Health, Safety, and Environment manager Randy Armstrong explained that the data gave residents the information they needed to decide for themselves where they wanted to live. There were places where the air was cleaner, he acknowledged, but those places might not have the kinds of amenities that one would enjoy in an industrialized area like Norco. Surveillance data, in this interpretation, was thus seen as a contributor to the risk-benefit calculations of community members. An empowered community was one made up of individuals with the ability to make informed choices.

While it is easy to criticize Shell's interpretation as spurious and self-serving (Norco, population 3600, is scarcely a "city" comparable to Houston or Minneapolis), the connection that it forges between environmental surveillance and a particular notion of empowerment-as-choice is nonetheless important. The version of empowerment constructed in the comparison of Norco's air monitoring data with that of other cities is influential and widespread: scholars from across the social sciences have shown empowerment organized around personal responsibility and individual choice to be part and parcel of neoliberal political projects (see for example Leve 2007; Vera-Sanso 2008) aimed at "extending and disseminating market values to all institutions and social action" (Brown 2003). Yet neoliberal logics have also been widely critiqued for their social and environmental consequences. Projects that individualize and/or privatize action on environmental issues, for example, have been shown to perpetuate 
inequalities, limit structural critique, and silence dissenting voices (Guldbrandsen and Holland 2001; Galusky 2003; Perkins 2009). To the extent that environmental surveillance data is interpreted to advance community members' power to choose, then, it would seem to support quite a limited form of empowerment, especially when contrasted with the power to define issues or even the power to participate in law enforcement sought by activists.

Additionally, interpretations geared toward choice-as-empowerment neglect the ways that negative datathat is, data showing evidence of poor air quality - can actually undermine residents' power to choose. Informed choice models poorly represent residents' reasons for living in fenceline communities from the start (see Ottinger forthcoming); however, community members deciding to move away based on (presumably empowering) data about local air quality would likely have difficulty selling their homes. Low property values and even red-lining-lenders' refusal to underwrite mortgages in certain neighborhoods - often characterize life in fenceline communities. Monitoring data showing air toxins in a neighborhood at unhealthy levels would likely only exacerbate these trends - and residents, figured as choosers in a free market, would find their practical opportunities to select a different place to live even more circumscribed.

\section{Levels of Empowerment}

A variety of possibilities exist for interpreting data collected through environmental surveillance of industrial facilities - whether by community groups or by facilities or regulators at residents' behest. They can be made meaningful in the context of corporate deceit and regulatory inadequacy, as in CCNS's presentations of bucket results. They can be compared to state regulations considered authoritative, as some of the data from Sentry monitoring in Chalmette were. And they can be interpreted in the context of the risk-benefit calculations that community members are presumed to make about where to live, as Shell's monitoring data were.

Choices about interpretive strategies have implications for community empowerment. Each of the three interpretations arguably enhanced community members' ability to act. However, the level at which they were empowered to act varied dramatically from one interpretation to another. CCNS's interpretation of bucket results supported a challenge to existing environmental regimes and power structures at the most fundamental level: by highlighting the unacknowledged impact of industrial pollution and the inadequacy of regulatory standards, bucket data allowed residents to redefine issues of air quality and force more powerful actors to react to attacks on their competence. The interpretation of Sentry data in the context of regulatory standards, in contrast, allowed Chalmette residents to intervene at a less foundational level, though possibly with more authority - temporarily abandoning their critique of regulatory standards, they used the infrastructure that the standards provided to exert influence on the neighboring refinery. Shell's interpretation of its monitoring data as empowering residents' choice, finally, focused on possibilities for action at an individual level, yet it ignored the structures that, in practice, constrain individual choice in fenceline communities and offered no opportunity for structural critique.

Understanding the contributions - or potential contributions-of surveillance to empowerment thus requires examining the processes by which surveillance data are made meaningful. Just because community groups have data about neighboring industrial facilities, it cannot be assumed that their ability to influence the powerful corporations that run them has been expanded. We must also ask how their data are translated into action or intervention; what kinds of intervention are made possible by various interpretations; and, to the extent that studies of surveillance and empowerment incorporate a normative project, how adequate the forms of empowerment enabled by various interpretations are to reducing social inequality. In the case of environmental surveillance of air quality, modes of interpretation that allow community members to question the ways that environmental issues are defined clearly make a greater contribution to ameliorating environmental injustices. Modes of interpretation that privilege individual 
choice, on the other hand, offer few possibilities for undermining structures of injustice and may even exacerbate them-making environmental surveillance one more example of the dis-empowering tendencies of neoliberal logics.

At a practical level, this analysis underscores the importance of interpretive choices for sousveillance practitioners. Different ways of making surveillance data meaningful structure the possibilities for intervention differently. Refusing the authority of regulatory standards as an interpretive infrastructure, for example, can allow for more fundamental challenges - but adopting the authority of standards may heighten a challenger group's influence.

Perhaps more importantly, this study suggests that the empowering potential of surveillance-from-below rests in large part on the ability of sousveillance practitioners to control interpretive choices. A community group would never interpret data from air sampling in the context of personal choices the way that Shell did. However, as environmental surveillance increasingly uses the Sentry and comparable realtime monitoring devices that generate an enormous volume of data, community groups, lacking scientific or statistical expertise, are becoming less and less able to interpret surveillance data on their own. With regulatory agencies and industrial facilities more likely to be involved in the interpretation of data, environmental justice activists who championed real-time monitors, thinking they would extend the kind of empowerment supported by buckets, may find their copious data interpreted in ways that restrict rather than expand their ability to influence industrial facilities.

\section{Acknowledgements}

The author would like to thank organizers (Torin Monahan, Jill Fisher, Gary Marx, and Simon Cole) and participants in the 2009 Surveillance and Empowerment workshop at Vanderbilt University; the paper owes much to the workshop's lively and thoughtful discussions. The author would also like to thank two anonymous reviewers, whose comments improved the paper.

\section{References}

Allen, Barbara L. 2000. The Popular Geography of Illness in the Industrial Corridor. In Transforming New Orleans and its Environs: Centuries of Change, ed. C. E. Colten. Pittsburgh: University of Pittsburgh Press.

Brown, Wendy. 2003. Neo-liberalism and the End of Liberal Democracy. Theory and Event 7.

Bryant, Bunyan. 1995. Issues and Potential Policies and Solutions for Environmental Justice: An Overview. In Environmental Justice: Issues, Policies, and Solutions, ed. B. Bryant. Washington, DC: Island Press.

Cannizaro, Steve, and Sandra Barbier. 2005. Device to check air near refinery; Chalmette activists to post results online. TimesPicayune, April 21, 2005, 1.

Collins, Jane L., Micaela di Leonardo, and Brett Williams, eds. 2008. New Landscapes of Inequality: Neoliberalism and the Erosion of Democracy in America. Santa Fe: School for Advanced Research Press.

Doherty, Joe, Volker Busch-Geertsema, Vita Karpuskiene, Jukka Korhonen, Eoin O'Sullivan, Ingrid Sahlin, Antonio Tosi, Agostino Petrillo, and Julia Wyngnanska. 2008. Homelessness and Exclusion: Regulating public space in European Cities. Surveillance \& Society 5: 290 - 314.

Frickel, Scott. 2008. On Missing New Orleans: Lost Knowledge and Knowledge Gaps in an Urban Hazardscape. Environmental History 13: 643 - 650 .

Frickel, Scott, Sahra Gibbon, Jeff Howard, Joanna Kepner, Gwen Ottinger, and David J. Hess. 2010. What's to be Done with Undone Science?: Charting Social Movement Challenges to Dominant Scientific Practice. Science, Technology, and Human Values 35.

Gad, Christopher, and Peter Lauritsen. 2009. Situated Surveillance: An ethnographic study of fisheries inspection in Denmark. Surveillance \& Society 7: 49 - 57.

Galusky, Wyatt. 2003. Identifying with Information: Citizen Empowerment, the Internet, and the Environmental Anti-Toxins Movement. In Cyberactivism: online activism in theory and practice, eds M. McCaughey and M. D. Ayers. New York: Routledge.

Guldbrandsen, Thaddeus C., and Dorothy Holland. 2001. Encounters with the Super-Citizen: Neoliberalism, Environmental Activism, and the American Heritage Rivers Initiative. Anthropological Quarterly 74: 124 - 134.

Guzik, Keith. 2009. Discrimination by Design: Data Mining in the United States's "War on Terrorism". Surveillance \& Society 7 : $1-17$.

Head, Rebecca A. 1995. Health-Based Standards: What Role in Environmental Justice. In Environmental Justice: Issues, Policies, Solutions, ed. B. Bryant. Washington, DC: Island Press. 
Hess, David J. 2007. Alternative Pathways in Science and Industry: Activism, Innovation, and the Environment in an Era of Globalization. In Urban and Industrial Environments, ed. R. Gottlieb. Cambridge, MA: The MIT Press.

Kenner, Alison Marie. 2008. Securing the Elderly Body: Dementia, Surveillance, and the Politics of "Aging in Place". Surveillance \& Society 5: 252 - 269.

Larson, Denny. 2002. Bucket Brigade Strikes Again - Telling Toxic Truth. Austin, TX: Refinery Reform Campaign. 2006. Crime Scene Investigation: Tools you can use to catch and expose pollution. In Good Neighbor Campaign Handbook: How to Win, ed. P. Ryder. New York: iUniverse, Inc.

Leve, Lauren. 2007. "Failed Development" and Rural Revolution in Nepal: Rethinking Subaltern Consciousness and Women's Empowerment. Anthropological Quarterly 80: 127 - 172.

Louisiana Bucket Brigade. n.d. Chalmette: Profile [cited March 29 2010]. Available from http://www.labucketbrigade.org/article.php?list=type\&type=154.

Lyon, David. 2001. Surveillance Society: Monitoring Everyday Life. Buckingham: Open University Press.

Mann, Steve, Jason Nolan, and Barry Wellman. 2003. Sousveillance: Inventing and Using Wearable Computing Devices for Data Collection in Surveillance Environments. Surveillance \& Society 1: 331 - 355.

Marx, Gary T. 2003. A Tack in the Shoe: Neutralizing and Resisting the New Surveillance. Journal of Social Issues 59.

Minnaar, Anthony. 2007. The implementation and impact of crime prevention / crime control open street Closed-Circuit Television surveillance in South African Central Business Districts. Surveillance \& Society 4: 174 - 207.

Monahan, Torin. 2006. Counter-surveillance as political intervention? Social Semiotics 16: 515 - 534.

Monahan, Torin, and Tyler Wall. 2007. Somatic Surveillance: Corporeal Control through Information Networks. Surveillance \& Society 4: 154 - 173.

O'Rourke, Dara, and Gregg P. Macey. 2003. Community Environmental Policing: Assessing New Strategies of Public Participation in Environmental Regulation. Journal of Policy Analysis and Management 22: 383 - 414.

Ottinger, Gwen. 2005. Grounds for Action: Community and Science in Environmental Controversy. Doctoral Dissertation, Energy and Resources Group, University of California, Berkeley, Berkeley.

2010. Buckets of Resistance: Standards and the Effectiveness of Citizen Science. Science, Technology, and Human Values 35: 244 - 270.

- Forthcoming. Refining Expertise: How Responsible Engineers Subvert Environmental Justice Challenges. New York: New York University Press.

Overdevest, Christine, and Brian Mayer. 2008. Harnessing the Power of Information through Community Monitoring: Insights from Social Science. Texas Law Review 86: 1493 - 1526.

Pallitto, Robert, and Josiah Heyman. 2008. Theorizing Cross-Border Mobility: Surveillance, Security, and Identity. Surveillance \& Society 5: $315-333$.

Perkins, Harold A. 2009. Turning Feral Places into Trendy Spaces: a coffee house in every park? Environment and Planning A 41: 2615 - 2632.

Rolfes, Anne, and Ken Ford. 2005. First Results from Chalmette Air Monitors Expose Pollution. Press Release, May 11, 2005.

Ryder, Paul, ed. 2006. Good Neighbor Campaign Handbook: How to Win. New York: iUniverse, Inc.

Sanborn, Rebecca. 2005. The Bucket Overflows. E: The Environmental Magazine, May/June 2005.

Tesh, Sylvia Noble. 2000. Uncertain Hazards: Environmental Activists and Scientific Proof. Ithaca: Cornell University Press.

Vera-Sanso, Penny. 2008. "Whose Money is It?: On misconceiving female autonomy and economic empowerment in low-income households. IDS Bulletin 39: 51 - 59.

Willse, Craig. 2008. "Universal Data Elements," or the Biopolitical Life of Homeless Populations. Surveillance \& Society 5: $227-$ 251. 